\section{Menopausa, hormônios, envelhecimento: discursos de mulheres que vivem em um bairro na periferia da cidade de São Paulo, Estado de São Paulo, Brasil}

\section{Menopause, hormones, aging: the discourse of women living on the outskirts of the city of São Paulo, State of São Paulo, Brazil}

Belkis Trench1

Tereza Etsuko da Costa Rosa2

1,2 Instituto de Saúde. Secretaria de Estado da Saúde de São Paulo. Rua Santo Antonio, 590. São Paulo, SP, Brasil. CEP: 01.314-000. E-mail: belkis@usp.br; belkis@isaude.sp.gov.br

\begin{abstract}
Objectives: to analize the discourse regarding the menopause in women attending a health service unit on the outskirts of the city of São Paulo, State of São Paulo, Brazil, in order to understand the meaning they attribute to this event.

Methods: eight women aged between 44 and 75 years were interviewed using qualitative methods and a social constructionist approach. The data were collected using participant observation, life histories and interviews.

Results: in the group of study the menopause is experienced by these women as an inevitable occurrence related to their bodies and lives and is also considered a strange inimical event that afflicts them unexpectedly.

Conclusions: in ghe group of study the results indicate how important it is to approach the menopause is such a way that is viewed as something relative and particular to each individual, not as something universal and standardized.
\end{abstract}

Key words Menopause, Aging, Women's health, Basic health services

\section{Resumo}

Objetivos: analisar os discursos de mulheres usuárias de unidade básica de saúde da periferia da cidade de São Paulo, no estado de São Paulo, Brazil, sobre a menopausa para compreender os sentidos que elas atribuem a este evento.

Métodos: foram entrevistadas oito mulheres entre 44 e 75 anos, empregando-se a metodologia qualitativa na perspectiva do construcionismo social, de modo que os dados foram coletados por meio de observação participante, história de vida e entrevistas.

Resultados: nas mulheres estudadas, a menopausa é vivida de modo geral como um acontecimento inevitável, relacionado ao corpo e à vida, e é considerada uma entidade estranha, ou inimiga, que ataca as mulheres de maneira inesperada.

Conclusões: nas mulheres estudadas os resultados indicam que este periodo deve ser percebido em seu caráter particular e relativo, não como sendo da ordem do universal ou como algo padronizado.

Palavras-chave Menopausa, Envelhecimento, Saúde da mulher, Serviços básicos de saúde 


\section{Introdução}

A menopausa (ou o término da vida reprodutiva) é tratada em nossa cultura como um dos principais marcos do envelhecimento feminino, e é como tal que os discursos biomédicos se apropriam deste acontecimento, estabelecendo um movimento de vinculação entre essa etapa, o envelhecimento e a patologia.1,2 Os meios para que essa associação seja desfeita seriam, grosso modo: prevenção, hormônios, rejuvenescimento.

Pode-se atribuir especialmente a Wilson ${ }^{3}$ e a sua obra "Femine forever" grande parte da responsabilidade pela construção, estabelecimento e disseminação desse tipo de vínculo associativo. A primeira edição do livro foi lançada em 1966, nos Estados Unidos, e "vendeu mais de 100.000 exemplares apenas no primeiro ano" (Sellman, 1996: 1). 4 No Brasil a obra foi traduzida pelos Luiz e Lucinda Corrêa de Brito e publicada pela editora Edameris no mesmo ano. No comentário feito na 'orelha' do livro da edição brasileira e escrito por Reginaldo Halash, a terapêutica de Wilson é enaltecida da seguinte maneira:

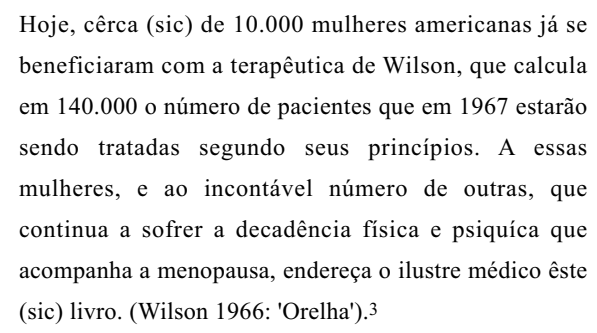

No livro, cujo título por si só já é sugestivo, Wilson parte do princípio de que o fim da vida reprodutiva é uma espécie de morte em vida das mulheres. A prescrição de hormônios, nesta perpectiva, teria o objetivo de salvá-las desta espécie de condenação ou, como diz o autor:

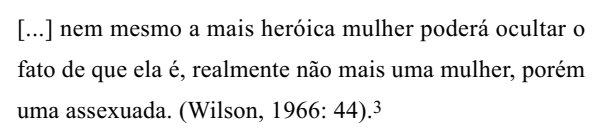

A menopausa, ainda segundo Wilson ${ }^{3}$, não só deve ser abordada como um problema médico relevante da sociedade moderna como o seu tratamento e a cura tornam-se, assim, uma obrigação social e moral, de modo que, para tanto, a menopausa deve ser compreendida não mais como mais um "ato do destino", mas como uma grave moléstia de privação, em muitos aspectos semelhante ao diabetes. Neste sentido, verifique-se como este autor cita a sua experiência clínica e estabelece a analogia entre menopausa e diabetes:

Para curar a diabetes (sic), suprimimos a substância ausente com a insulina. Uma lógica similar pode ser aplicada à menopausa $[\ldots]$ os hormônios que faltam podem ser substituídos. (Wilson, 1966: 20). ${ }^{3}$

Ainda que as proposições de Wilson tenham sido duramente criticadas, especialmente por autoras feministas, 5 e alguns dos benefícios atribuídos à terapia de reposição hormonal (TRH) serem alvo recentemente de extensa polêmica, 6,7 observa-se que continuam sendo estas as principais premissas, ainda que modernizadas, que norteiam o discurso médico hegêmonico sobre a mulher na menopausa. ${ }^{8}$

Para que os hormônios sejam consumidos pelas mulheres na menopausa, não só as associações entre 'hormônios e rejuvenescimento' e 'hormônios e prevenção' deverão estar em constante circulação no imaginário, como também os médicos terão de ser parte integrante dessa cadeia associativa e constituirse como o mais importante vetor para sua disseminação.9,10 Assim, é necessário que o médico extrapole o seu papel de prescritor legitimado e assuma também a função de imagem legitimadora desta prática de consumo. 11

Além disso, o marketing dos laboratórios farmacêuticos, atentos a esse mercado, se apropria desse imaginário e concentra todos os seus esforços em disseminar os benefícios da TRH,1,12,13 especialmente entre aqueles que teriam o poder de legitimar os seus produtos: os especialistas - até porque a propaganda de medicamentos é vetada junto ao público leigo. De outro lado, para que as mulheres compartilhem desse imaginário e sejam submetidas à TRH, além de apresentarem os ditos sintomas associados à menopausa, terão também de satisfazer outras condições mínimas, a saber: a) disponibilidade de recursos financeiros para comprar o medicamento; b) acesso a um acompanhamento médico sistemático e aos exames de controle sofisticados tais como ultra-som e mamografia (condição que, no caso do Brasil, é estritamente ligada à condição anterior).

Nesse aspecto, observa-se que a construção dos sentidos da menopausa e de sua medicalização, tal como é hoje disseminada, tem como público alvo uma mulher social e economicamente diferenciada, intelectualmente refinada e com tempo e dinheiro disponíveis para cumprir os demais rituais que a ela são atribuídos como medidas complementares: longas caminhadas, exercícios fisícos, cremes, vitaminas, alimentação balanceada, etc. 
Tal construção não só nega a alteridade e a diferença, como parte do pressuposto de que as questões relacionadas à menopausa e ao envelhecimento se apresentam igualitariamente às mulheres, independentemente das suas singularidades e inserção socioeconômica e cultural. O mesmo perfil de mulheres é o objeto predominante de estudos sobre menopausa nas Ciências Sociais e Humanas, como mostram diversos trabalhos, ${ }^{14-16}$ e os raros estudos que focalizam menopausa e classes sociais, 17,18 parecem não identificar diferenças significativas entre os sintomas e vivências da menopausa nos diversos segmentos sociais.

Partindo de tais considerações, o presente artigo apresenta os resultados de um estudo realizado com mulheres que vivem em um bairro na periferia da cidade de São Paulo, usuárias de uma Unidade Básica de Saúde, cujo objetivo foi investigar a menopausa sob a perspectiva de um segmento de mulheres que, por suas condições socioeconômicas e culturais, são excluí-das do imaginário oficial ligado ao tema.

\section{Métodos}

Este estudo é parte integrante de um projeto mais amplo de pesquisa - Projeto Ondas - cujo objetivo foi ampliar o conhecimento sobre a menopausa e sua medicalização em nosso meio. A pesquisa mais ampla, realizado em 2003 e 2004, envolveu três campos de pesquisa, todos no estado de São Paulo, com mulheres usuárias de duas unidades públicas de saúde - uma no município de São Sebastião, outra no de São Paulo, e com índias que viviam na aldeia do Rio Silveira, entre os municipios litorâneos de Bertioga e de São Sebastião.

O presente trabalho diz respeito somente a um dos campos de investigação do projeto: as mulheres que viviam no bairro de São José, periferia do município de São Paulo, e que eram usuárias da Unidade Básica de Saúde (UBS) do local.

O bairro pertence ao subdistrito de Cidade Dutra da Subprefeitura de Capela do Socorro, e está localizado no extremo sul do município de São Paulo, Estado de São Paulo. A UBS foi escolhida por ser um dos locais que pareceu melhor contemplar os interesses desta pesquisa, já que é apontado por profissionais de saúde que atuam na região como de público homogêneo, constituído pela a população de baixa renda.

Optou-se pela metodologia qualitativa na perspectiva do construcionismo social, 19 tendo sido utilizadas diferentes técnicas para obtenção dos dados, tais como observação participante, relato de história de vida e entrevistas abertas com foco sobre a menopausa, gravadas na íntegra por meio de uma câmara mini-DV (com exceção da entrevista com o especialista). Vale ressaltar que, aqui, a imagem foi utilizada como instrumento de coleta de dados, modo de construir conhecimento desenvolvido por uma especialidade da Antropologia, qual seja, a Antropologia Visual ou Antropologia Fílmica.

Outros dados também foram registrados por meio de diário de campo, gravações (sem câmera) e fotografias. Esses foram utilizados principalmente para as anotações e registros realizados durante as visitas ao bairro, cujo intuito era compreender o entorno da unidade de saúde e o dia-a-dia da comunidade, do mesmo modo como acontece com os estudos de caráter etnográfico.

Considerando o desconhecimento do fluxo de atendimentos na UBS, o vínculo estabelecido entre médicos e pacientes, e até mesmo o tipo de atendimento prestado às mulheres da faixa etária estudada, a compreensão dessas dinâmicas institucionais foi obtida por meio da observação participante e de uma entrevista com um dos médicos da especialidade de ginecologia da unidade.

$\mathrm{Na}$ entrevista com o médico especialista (que não permitiu que a entrevista fosse registrada com gravação) abordaram-se os seguintes temas: envelhecimento e gêneros sexuais, a medicalização do envelhecimento, bem como a sua postura em relação ao tema da menopausa. Não obstante seu depoimento tenha sido importante, foi utilizado apenas como dado complementar da pesquisa, pois o cerne da investigação recaía sobre as mulheres.

Foram entrevistadas para a pesquisa oito mulheres de 44 a 75 anos de idade, sendo que, segundo as normas da Organização Mundial de Saúde, duas delas se encontravam no período da prémenopausa, três na menopausa e as demais na pósmenopausa. ${ }^{20}$ Algumas delas foram recrutadas no próprio serviço de saúde e outras diretamente abordadas em suas residências. A maioria dos depoimentos foi coletado nas casas das mulheres e alguns na unidade de saúde, por condição imposta pelas entrevistadas. Duas das entrevistadas eram mãe e filha e foram incluídas no universo da pesquisa porque atendiam ao critério da faixa etária. No entanto, quando outros familiares participavam espontaneamente das entrevistas, foram considerados apenas como coadjuvantes da pesquisa.

A entrevista se iniciava a partir da história de vida das investigadas e aprofundava-se com os seguintes temas: menopausa, sintomatologia, medicamentos, tratamento, sexualidade e relação com os serviços de saúde. As entrevistas e histórias 
de vida gravadas foram transcritas e as imagens coletadas foram transferidas para o computador para facilitar a análise do material.

Com o intuito de ampliar a nossa compreensão sobre a localidade e obter informações sobre o cotidiano do bairro, mantivemos contatos com outras diversas pessoas, tais como comerciantes e feirantes, e seus depoimentos foram colhidos informalmente.

Para a análise dos depoimentos foi adotado, na maioria das vezes, o seguinte procedimento: lia-se a entrevista transcrita, assinalavam-se os trechos que pareciam estar mais relacionados com o tema em questão, em seguida, assistia-se aos filmes. Com tal metodologia pudemos chegar a uma compreensão do que diz Joly (2001: 15):21

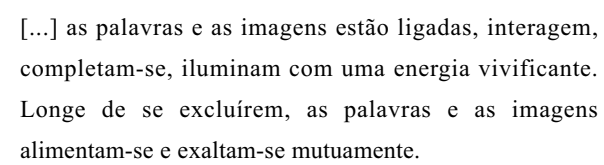

O "Projeto Ondas", anteriormente citado, foi submetido e aprovado pelo Comitê de Ética do Instituto de Saúde da Secretaria de Estado da Saúde de São Paulo. Todas as pessoas entrevistadas assinaram o Termo de Consentimento Livre e Esclarecido, e autorizaram o uso de seus depoimentos e imagens para fins científicos. No caso do artigo, foi mantido o anonimato de suas identidades, utilizando-se nomes fictícios.

\section{Resultados}

Inicialmente, faz-se uma sucinta descrição do contexto de vida e do dia-a-dia da comunidade das mulheres que participaram do estudo, compreendendo-os como o contexto em que as práticas discursivas dessas mulheres se desenvolvem e que, portanto, serve de principal subsídio para a apreensão dos processos de produção de sentidos 19 acerca da menopausa e do envelhecimento. A seguir, apresentam-se os conteúdos verbais selecionados a partir de todo o processo de análise das informações coletadas na pesquisa (entrevistas, filmagem das entrevistas e inúmeras visitas ao local).

\section{O contexto de vida}

O bairro de São José se assemelha a uma pequena cidade nordestina, devido aos sotaques, expressões lingüísticas e músicas daquela região, bem como aos vários estabelecimentos especializados em comidas e produtos nordestinos, como carne de sol, manteiga de garrafa, buchada e sarapatel. Porém, a predominância de moradores originários do Nordeste é efetiva apenas em determinadas áreas. Em outras, mais nobres e valorizadas, eles estão ausentes. O local de moradia de nossas entrevistadas consistia em moradias aglomeradas, ou favelas, caracterizando-se, portanto, pelo convívio de diferentes famílias. Ressalte-se que das entrevistadas da pesquisa, apenas uma não nasceu no Nordeste.

Os bens materiais deste bairro parecem quase sempre desempenhar mais de uma função utilitária: uma casa pode ser um lar, mas seu terraço ou garagem da noite para o dia pode se transformar em bar ou mercearia; uma parede dá sustento a uma edificação e é também um outdoor que divulga o serviço que seu morador oferece à comunidade - por exemplo, fazer bolos de festa; uma caminhonete transporta a família, e divulga o ofício do serralheiro.

Tal como acontece em pequenas cidades do Nordeste, o grande evento da semana é a feira livre. No dia da feira, a avenida também se transforma em um grande brechó a céu aberto: algumas pessoas dispõem uma grande quantidade de sapatos e roupas usadas sobre as calçadas e os interessados experimentam o produto na rua mesmo. Observa-se que as estratégias de sobrevivência dessa população são as mais diversas: de um lado, apontam para a adversidade de suas condições de vida; de outro, para o que Certeau22 chama de "astúcias sutis", táticas de resistência pelas quais as pessoas alteram os objetos e os códigos e se apropriam do espaço e do uso a seu jeito. Das entrevistadas da pesquisa apenas duas trabalham formalmente, enquanto as demais vivem da aposentadoria ou de pequenos "bicos".

Em relação aos equipamentos de saúde da localidade, a UBS "Dr. Sérgio Chadad", principal referência de atendimento médico, localizada na avenida principal do bairro, foi fundada em outubro de 1973 e é conhecida por todos moradores, ainda que nem todos se utilizem exclusivamente deste serviço. Em relação à menopausa, não existe um programa de saúde específico destinado a mulheres nessa faixa etária, o foco da atenção é a saúde reprodutiva e a prevenção de doenças crônicas, tais como diabetes e hipertensão arterial. O único ginecologista entrevistado foi muito reticente no que diz respeito a um tratamento específico da menopausa na UBS, disse que as queixas mais freqüentes estão relacionadas a nervosismo e ondas de calor, e raramente indica a TRH, devido às dificuldades de acompanhar sistematicamente as pacientes, realizar exames complementares e também devido ao custo dos medicamentos. Quando as pacientes relatam sintomas insuportáveis, ele receita isoflavona ou hormônio injetável. 
O grande rodízio dos profissionais de saúde desfavorece a criação de vínculo entre pacientes e médicos, além de provocar a descontinuidade do tratamento prescrito:

[...] a gente começa a fazer um tratamento, os médicos saem daí e a gente nunca termina. (Helena, 44 anos).

Observou-se por meio dos diversos relatos que a população se relaciona com os equipamentos de saúde de uma forma bastante peculiar: em casos de emergência, buscam o atendimento fora da localidade; para algumas especialidades, vão nessa ou naquela unidade básica de saúde; para realização de exames, procuram o local com menor tempo de espera. Quando percebem que o caso é grave e sabem que a espera pode comprometer a saúde, pagam uma consulta em uma clínica particular, que fica na mesma rua da UBS e oferece consultas e exames a baixo custo. $\mathrm{O}$ mesmo parece ocorrer em relação à realização dos exames preventivos preconizados pelos programas de saúde da mulher, já que os usuários percebem que a execução desses exames muitas vezes os obriga a peregrinar por diferentes serviços para tentar driblar a espera, frequentemente de mais de três meses, mesmo que para realizar uma simples mamografia.

\section{Os discursos}

Nas entrevistas que trataram propriamente da menopausa, chama a atenção o modo como a palavra aparece poucas vezes nos depoimentos. É freqüentemente substituída por expressões como: "esse negócio", "ela" ou "isso". Da mesma forma, tem-se a impressão de que a menopausa é um acontecimento da ordem do inesperado e, tal como um inimigo ou bandido, ataca as mulheres, pegando-as desprevenidas: "A menopausa me pegou, e eu quase ignorante no assunto", ou: "esse negócio de menopausa me atacou muito", dizem Elizângela, 65, e Helena, 44 anos.

A menopausa adquire esse sentido especialmente para as mulheres mais velhas, que alegam pouca experiência, ignorância e falta de divulgação de informações, inclusive por parte dos médicos. Quem melhor sintetiza esse sentimento é Laura, 71: "... eu tava inocente, era inocente". As mulheres mais jovens, mesmo sem ter vivido esta experiência, por ouvirem relatos de mães, irmãs ou amigas, associam a menopausa a coisas ruins, sofrimento e principalmente à difícil experiência da oscilação brusca da temperatura corporal.
[...] deve ser uma coisa ruim! Porque minha irmã sofre com isso. Às vezes à noite ela não consegue dormir. Quando dorme, dorme sem roupa. [...] De repente começa a pingar, pode estar o frio que estiver, depois começa o frio, dá um calorzão, depois dá um frio. Deve ser uma coisa ruim, também isso, não é? (Cláudia, 44 anos).

De tanto ouvir as queixas e para não passar pelos mesmos problemas, a filha de Elizângela, que tem apenas 28 anos, resolveu procurar um ginecologista para saber se deveria começar a ingerir soja. Cláudia é outra entrevistada que se preocupa com o tema e para evitar os problemas, já que tem 44 anos, pretende começar a se cuidar:

[...] a gente tem que se cuidar, a partir de 35 anos, pelo menos aqui no posto dizem, mas fui no convênio direto, falaram que eu não tinha idade para isso. Mas agora eu sei que eu tenho idade pra isso, já: eu tenho 44 anos. Já começou esse calorzão. Sinal que já é hora.

Helena, também com 44 anos, no momento não se preocupa com a menopausa ou em fazer qualquer tipo de prevenção, já que seu maior problema não é a falta e sim o excesso de menstruação, causado, segundo explica:

[...] estar com os nervos abalados, fracos [...] ela não tem mais regulagem, não posso nem usar absorvente, porque desce demais pra mim. Eu usava modess, e pronto, ficava por isso. Agora estou usando é fralda. Porque quando está para descer pra mim, os peitos doem muito, e passo de uma semana a duas sentindo cólica. Aí tenho que tomar remédio, só que o doutor disse que não é pra eu estar fazendo isso agora, por causa do problema da pressão, dos nervos, que eu estou com os nervos abalados, meus nervos começaram a ficar fracos.

"O calor", "o calorzão", "a caloria", "a cabeça pegando fogo", "o suor pingando", "ficar vermelha como um camarão", "sufoco", "suadeira", "o corpo cheio de formiga" são algumas das palavras e expressões que elas usam para nomear os temidos fogachos, ou ondas de calor. Até mesmo Sílvia, que tem 75 anos, ainda reclama do incômodo causado pelo calor, atribuindo a persistência dos sintomas ao fato de ter menstruado com 15 anos e sua menopausa ter ocorrido aos 56 anos.

[...] eu, minha filha, não posso nem explicar pra você o que é. Eu sei que até hoje a temperatura do meu corpo manda fogo. Tem noite que eu não posso nem dormir com meus pés, passo no médico e o médico diz que é porque 
com 56 anos eu ainda tinha, ainda descia para mim. Eu fui moça já muito tarde, tinha quase quinze anos.

Vânia, de 52 anos, filha de Sílvia, também fala do desconforto que sente:

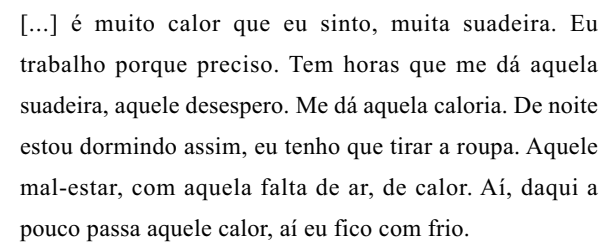

Seus calores começaram antes mesmo que ela completasse os 50 anos. O calor, além de desconforto, causava-lhe embaraço e vergonha, sobretudo quando estava no ônibus. Com o tempo os sintomas foram se transformando e hoje, talvez porque esteja em casa repousando, o calor também está se aquietando:

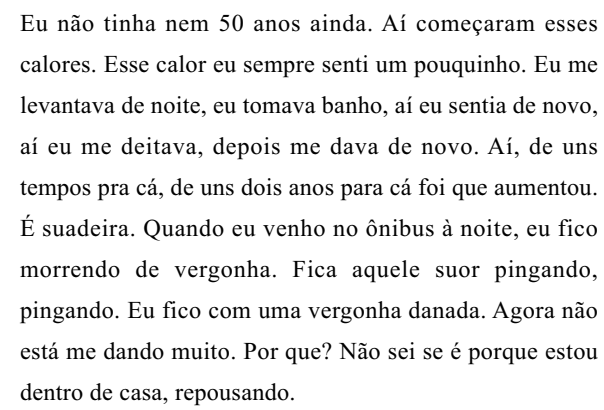

Roberta, 58, é outra entrevistada que também se queixa da menopausa. Conta que sentia um calor infernal, tomava banho o dia inteiro e à noite tinha que dormir sem roupa. Da mesma forma que vinha o calor, também vinha um grande frio. Outro sintoma que atribui à menopausa são as dores nas pernas e juntas. E para concluir diz:

\section{[...] a minha foi assim, e acho que a da maioria.}

Já Elizângela, 65, não reclama das ondas de calor, mas associa a menopausa às expressões "sufoco", "passar mal", "sofrimento" e "hemorragia", e atribui à falta de diálogo com os médicos e aos medicamentos então prescritos o que chama de seqüelas desta época:

Menopausa é um sufoco, é muito difícil. Eu passei muito mal por causa da menopausa.[...] Os médicos, também, antigamente, eles não falavam. A gente ia ao médico e eles não mantinham um diálogo com o paciente. Então era, como eu disse, ignorante no assunto, então eu sofri muito, tive muita hemorragia. Então tomei drogas que não devia tomar, sei lá. E eu fiquei com problemas de osso. Mas passou, só que ficaram seqüelas.

Das entrevistadas mais velhas, apenas Laura, 71, e Olga, 57, é que não fazem nenhuma queixa em relação à menopausa. Laura, como já foi dito, porque diz que era inocente, ou seja, nem sabia que a menopausa podia gerar tantas polêmicas; já Olga não se queixa porque associa menopausa a quem tem vida sexual:

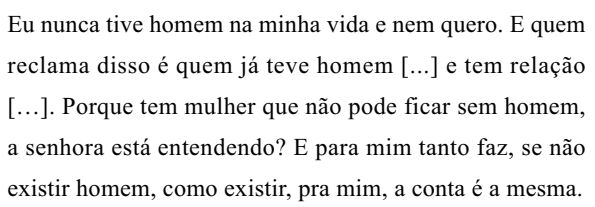

Embora a maioria das entrevistadas atribua à menopausa um sentido negativo, ou até mesmo a considere como uma espécie de doença, com exceção do calor, as demais queixas parecem estar relacionadas a outras questões de saúde, tais como, hipertensão, mioma e problemas de circulação. Sobre a sintomatologia que envolve aspectos emocionais ou mudança de comportamento, as principais questões levantadas dizem respeito à falta de libido e irritação.

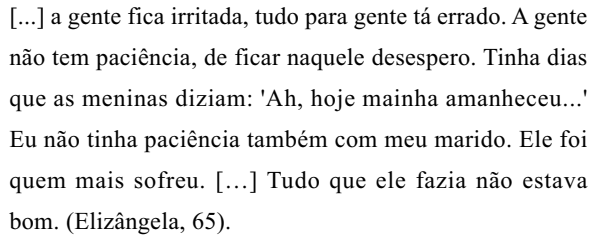

No depoimento de Laura, 71, chama a atenção o fato de ter tomado medicação, especialmente por ser ela uma das únicas que não se queixa dos sintomas da menopausa:

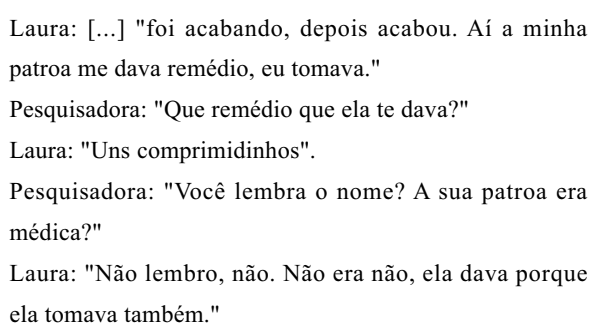

A propósito, a ingestão de medicamentos pelas entrevistadas para minimizar os sintomas da menopausa, mesmo quando indicados por médicos, é uma questão preocupante, porque a maioria delas 
parece desconhecer a necessidade de acompanhamento médico sistemático e principalmente porque tendem a atribuir à menopausa as mais diferentes patologias. Os dois depoimentos que transcrevemos abaixo exemplificam essa situação. Vânia, 52, diz que tomou uma injeção para melhorar o calor:

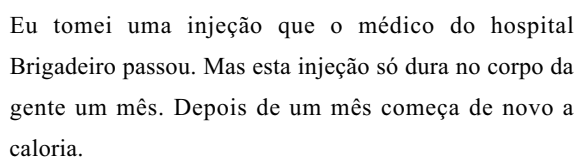

Relata ainda, que depois de um curto período, procurou um outro médico da UBS, que lhe disse que deveria procurar um ginecologista:

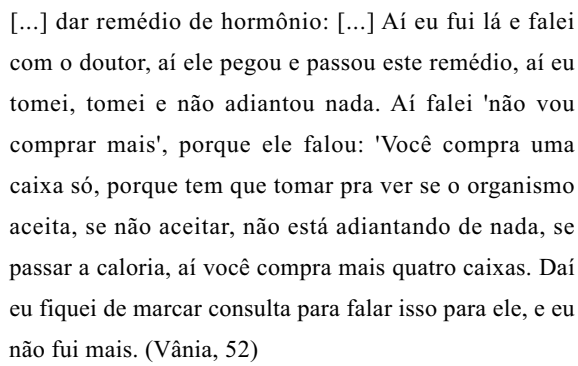

Helena, 44, é outra entrevistada que relata que fez tratamento para a menopausa. Sua filha, presente na entrevista, lembra que foi ela que a levou ao médico e conta sobre os sintomas que sua mãe sentia, justificando o tratamento:

Eu via ela chorando com dor nas pernas, dor nos braços. Eu era mocinha, eu esquentava água, passava água quente no pé dela. Aí que foi que eu levei ela num médico. Aí que o médico falou que aquilo que ela sentia era menopausa. Aí foi que ele passou bastante remédio para ela.

Pesquisadora: "E a senhora chorava por quê?"

$[\ldots]$ era muita dor forte, dor nas pernas [...] Eu trabalhava com aquela máquina de lavar chão, sabe? Um dia atacou que eu caí, quase que enrolava tudo, se não fossem os guardas, eu tinha pagado o prejuízo. (Helena, 44 anos)

Como as entrevistadas não mencionaram a palavra "envelhecimento" relacionando-a à menopausa, foi perguntado para elas com que idade achavam que as mulheres começavam a envelhecer. Apenas Roberta é que nomeou a menopausa como marco. As outras respostas foram as mais diversas. Cláudia, por exemplo, acha que a partir dos 30 anos uma mulher já está velha, não deveria nem mais ter filhos, e também diz que percebe que há mudanças no tratamento dado a ela por parte dos outros:

Eu não sei, pra mim, passou dos 30 já está bem velho, tanto que até pra pessoa ganhar um filho com 30 anos já é feio. Eu acho. Porque quando eu ganhei minha última filha eu tinha 24 anos. Eu creio que eu nunca pensei em ter filho velha. (Claúdia, 44 anos)

Para Olga, 57 anos, o envelhecimento das mulheres parece ser algo muito relativo:

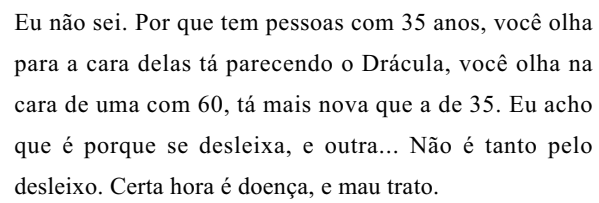

Laura pensa que a velhice começa aos 60 anos, já Vânia e Sílvia (mãe e filha), ficam na dúvida, pois muitos dizem que a vida começa aos 40 :

Depois dos 40 a pessoa já começa a envelhecer, mas tem muita gente que fala que a vida começa depois dos 40 . Então, a gente não sabe. (Sílvia, 75 anos)

Quando foi perguntado a elas o que pensavam de suas idades, todas pareceram satisfeitas. Cláudia se sente privilegiada por ter chegado aos 44 , porque muitas pessoas nem chegam lá. Laura sente que agora não é mais jovem, é idosa, mas se dependesse de sua vontade nunca morreria. O que mais gosta da vida é dormir, acordar. Roberta não troca sua idade pela das filhas, que têm 20 anos, porque acha que as mulheres mais jovens não têm a mesma disposição que ela tinha. Já Elizângela pensa justamente o oposto de Roberta e acha que na juventude, "a gente cansa menos, a gente tem mais vigor", mas percebe que uma das vantagens do envelhecimento é a sabedoria e a experiência. Olga é a única que gostaria de ser mais velha, pois acha que saberia mais coisas sobre a vida. Já Sílvia diz que quando era jovem pensava que só queria "durar trinta anos", não queria ficar velha para ninguém tirar deboche $\mathrm{e}$ temia que o pessoal a transformasse em um "trem à toa". Agora que é "velha", não se arrepende de nada do que fez ou viveu, mas adoraria voltar ao tempo se pudesse, tal como pensa sua filha Vânia ao dizer: "Ah! seria uma maravilha. Quando passa o passado a gente vê que ele era muito bom". 


\section{Discussão}

Um dos primeiros aspectos que chama a atenção de quem investiga a menopausa é o quanto o tema provoca nessas mulheres sentimentos ambíguos: a menopausa tanto é vivida pelas entrevistadas como um acontecimento inevitável e relacionado aos seus corpos e as suas vidas, como é considerada uma entidade estranha, ou inimiga, e que as ataca de maneira inesperada. Talvez seja ainda este duplo sentimento que também as faça denominar a menopausa, como vimos em seus depoimentos, com expressões como: "esse negócio", "coisa ruim", "ela" ou "isso". Destituindo a menopausa de um nome próprio, parece que elas também a remetem para a ordem do não-dito e do inominável.

Já o mesmo não acontece em relação à sintomatologia, que aparece como algo da ordem do nominável, do sentido e do vivido. O famoso fogacho ou ondas de calor ocupam grande parte de suas queixas. O calor ou "caloria", como se referem, atacam tanto a cabeça delas - "cabeça pegando fogo" -, quanto a pele - "fica vermelha como um camarão" -, a temperatura do corpo todo, "que pega fogo", os pés, ou mesmo outras sensações corporais, como "corpo cheio de formiga". Associam ainda a estes sintomas o desconforto, as noites não dormidas, a suadeira e a vergonha.

Os fogachos são a queixas mais freqüentes não só de nossas entrevistadas como também de $70 \%$ das mulheres que se encontram na menopausa. 23 As ondas de calor, além de causarem desconforto, ainda despertam um sentimento muitas vezes mais difícil de suportar, a vergonha. Uma de nossas entrevistadas, por exemplo, relata claramente a vergonha que sentia quando o fogacho a atingia no transporte público. Outras mulheres relatam o mesmo sentimento em livros, alguns inclusive com título muito sugestivo, tais como o de Sand24: "Está quente aqui ou sou eu?".

Como compreender essa associação entre o fogacho e a vergonha?

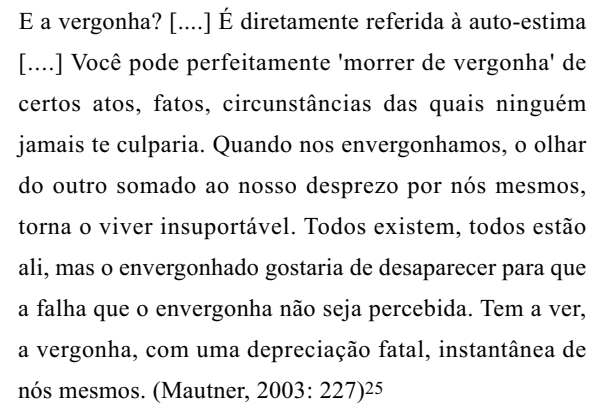

O fogacho parece causar vergonha nas mulheres porque é o único sintoma relacionado à menopausa que torna visível para o outro um acontecimento de suas vidas que elas não gostariam de tornar público ou exposto. $\mathrm{O}$ fato de a menopausa ainda ser vivida por grande parte delas associada a sentimentos de rebaixamento de sua feminilidade e de depreciação em relação a elas mesmas, contribui para que o rubor, o suor e o calor provocados pelo fogacho sejam percebidos como uma humilhação diante de outrem.

Já em outras culturas, o calor adquire outros sentidos. Por exemplo, para o povo Samo de Burkina Fasso, na África, é a categorização baseada no dualismo entre frio e quente que organiza os acontecimentos, os mecanismos de suas instituições e norteia as relações sociais. Nesse sistema, o sangue, por exemplo, pertence ao domínio do quente, porém é o homem, e não a mulher, que é considerado pertencente à categoria do quente, de modo que a pior injúria para o homem é dizer: "tu és fresco, tu és frio como uma mulher". (Héritier, 1998:77).26 O homem é considerado quente porque nessa cultura o esperma é sinônimo de sangue e de calor e, diferentemente da mulher, que armazena ou perde o sangue durante a gravidez e menstruação, o homem nunca perde o próprio sangue.

\footnotetext{
É próprio da alquimia masculina nesta cultura, o homem produzir calor sem cessar, ao produzir sangue, fonte e veículo do calor no corpo. (Héretier, 1998: 77). ${ }^{26}$
}

Para este povo, a mulher na menopausa que continua mantendo relações sexuais freqüentes corre o grande risco de ser acusada de bruxarias, pois o fato de não mais perder o sangue ou o calor lhe permite, segundo a crença, acumular um calor explosivo.

A propósito, uma de nossas entrevistadas, Olga, também faz uma relação surpreendente entre menopausa e a sexualidade, dizendo em seu depoimento: "quem reclama da menopausa é quem já teve homem, ou quem tem relação sexual". Ela é a única entrevistada que é solteira - as demais entrevistadas da pesquisa são ou já foram casadas, sendo que duas atualmente são viúvas, uma é divorciada e as outras continuam vivendo com seus companheiros.

Em relação à sexualidade, apenas duas mulheres casadas relatam mudanças na libido após a menopausa, entretanto também associam a este fato outras causas, tais como o cansaço devido ao trabalho excessivo, problemas de saúde ou conflitos com os companheiros.

A queda de libido, a secura vaginal ou a falta de interesse sexual pelo companheiro não parece ser um 
bom motivo que leve qualquer uma dessas mulheres a agendar ou procurar a ajuda de um especialista. Até porque, mesmo que quisessem, dificilmente as usuárias deste serviço de saúde encontrariam um médico disponível para a escuta dessas queixas, pois a organização desse serviço, principalmente no que diz respeito à duração da consulta, seria um fator que dificultaria a escuta de questões relacionadas à sexualidade feminina. Além disso, ficou evidente na entrevista realizada com o médico ginecologista uma postura que se caracterizou sobretudo pela ambivalência com que trata essas mulheres e essa fase da vida: de um lado é conivente com os discursos que associam a menopausa a doenças e, de outro, se exime de tratá-la como tal. A falta de ginecologistas nesta unidade de saúde, a postura do profissional em relação à menopausa, as dificuldades para a realização de exames e o perfil socioeconômico das mulheres desta localidade são elementos que colaboram para que elas não estejam incluídas no universo hegemônico dos discursos da menopausa. O principal benefício dessa exclusão é que, não sendo o principal alvo desse discurso, elas aparentemente se tornam mais imunes à medicalização: as palavras "hormônio", "estrogênio", "TRH", raramente aparecem associadas à menopausa e são praticamente desconhecidas para a maioria das entrevistadas, mesmo para aquelas que mencionam as palavras "prevenção" e "tratamento". A forte pressão de médicos e de companhias farmacêuticas com relação à adoção de terapias hormonais para a menopausa está até agora restrita a clínicas particulares e consultórios médicos. 27

Por outro lado, o fato de elas não fazerem parte deste público-alvo, não significa necessáriamente que tais mulheres sejam impermeáveis aos discursos hegemônicos produzidos sobre a menopausa e veiculados pela mídia, patroas ou médicos de clínicas populares. O principal risco, como pode ser observado nos depoimentos, é que essas mulheres venham a ingerir hormônios inadvertidamente, desconhecendo os seus efeitos e sem exigir um acompanhamento periódico e sistemático.

É perceptível, principalmente nos depoimentos das entrevistadas que se encontram na perimenopausa e na menopausa, a influência desses discursos na construção de seus universos simbólicos, apesar de partilharem significados sociais diferentes e nem mesmo se referirem em seus discursos às palavras associadas à TRH. No caso das entrevistadas mais velhas, ou na pós-menopausa, também é essa permeabilidade que possibilita que elas hoje ressignifiquem o que sentiram ou viveram no passado em relação à menopausa, seja um sintoma ou a falta de informação sobre o tema.

Os discursos das mulheres investigadas, em outros aspectos, se diferenciam tanto dos discursos hegemônicos produzidos pelos especialistas como dos que são atribuídos a mulheres de classes privilegiadas. A principal diferença é que em nenhum momento a menopausa, mesmo aparecendo em seus depoimentos vinculada a experiências negativas, adquire o sentido em suas vidas de ruptura, passagem ou crise relacionada ao envelhecimento ou de um marco importante que sinalize uma mudança em suas existências. Para tais mulheres, não só não existe espaço para viver a denominada crise da crítica, como também a menopausa é vivida sem as estreitas relações entre menopausa e envelhecimento e sintomas e terapia de reposição hormonal.

\section{Considerações finais}

Realizar um trabalho de investigação sobre o tema menopausa neste ou em outro campo de pesquisa, implica, em primeiro lugar, perceber a diversidade dos sentidos atribuídos ao fim do ciclo reprodutivo das mulheres e, sobretudo, o sentido que a menopausa adquire em cada vida. Em segundo lugar, investigar esse tema possibilita que se reflita sobre o papel desempenhado pelos diferentes discursos que circulam em nossa cultura para a manutenção do estigma associado à mulher que se encontra na menopausa e também, conseqüentemente, que se minimize a sua sintomatologia e o poder dado pelo discurso médico hegemônico à TRH.

Paradoxalmente, é essa diversidade de discursos e de sentidos sobre o tema que possibilita que a menopausa possa ser constantemente redimensionada, pois ela poderia ser considerada uma doença somente com a condição de que houvesse consenso ou unanimidade em tal direção, já que isto tornaria difícil questionar a sua construção e relativizar a sua sintomatologia.

Sendo assim, as políticas que tratam da saúde da mulher deveriam promover e disseminar a relativização e não buscar um consenso sobre o tema e, sobretudo, mostrar que por trás de um conceito existe uma história e uma singularidade inerentes a cada uma das pessoas que vivem essa fase da vida, o que também implica considerar as diferenças etárias, nível de escolaridade, socioeconômico, cultural e até mesmo de orientação sexual. Menopausa ou menopausas? Mais do que uma interrogação como qualquer outra, talvez seja essa a verdadeira questão a ser discutida e que dê ao tema a visibilidade merecida (Trench, 2005: 99). ${ }^{2}$ 


\section{Agradecimentos}

À Fundação de Apoio à Pesquisa do Estado de São Paulo (FAPESP), pelo apoio financeiro de todo o estudo (Auxílio à pesquisa, Processo 02/0341-4).

\section{Referências}

1. Oliveira MCFA. Às mulheres, os hormônios! Rev Bras Estudos Pop. 1992; 9:184-8.

2. Trench B, Santos CG. Menopausa ou menopausas? Saúde Soc. $2005 ; 14: 91-100$.

3. Wilson R. Eternamente feminina. São Paulo: Edameris; 1966.

4. Sellman S. Heresia hormonal - A verdade mortal sobre o estrogênio. 1996. Disponível em <URL: http://www.geocities.com/novatrh/perigo.html>. [2007 ago 27].

5. Greer G. Mulher, maturidade e mudança. São Paulo: Augustus; 1994

6. Nelson HD, Humphrey LL, Nygren P, Teutsch SM, Allan JD Postmenopausal hormone replacement therapy: scientific review. JAMA. 2002; 288: 872-81.

7. Lacey JV, Mink PJ, Lubin JH, Sherman ME, Troisi R, Hartge $\mathrm{P}$, Schatzkin A, Schairer C. Menopausal hormone replacement therapy and risk of ovarian cancer. JAMA. 2002; 288: 368-9.

8. Pinotti JA, Halbe HW, Hegg R. Menopausa. São Paulo: Rocca; 1995.

9. Trench B. Com regras, sem pausa: imagens da mulher na menopausa em anúncios de laboratórios farmacêuticos. In: Resumos do II Enconto de Estudos de Gênero; 2001 24-27 out.;Curitiba, Paraná. Curitiba; 2001. p. 6

10. Trench B. À saúde da mulher: reflexões sobre o envelhecer. In: Litivoc J, Brito FC, organizadores. Envelhecimento: prevenção e promoção da saúde. São Paulo: Atheneu; 2004 p. 189-202.

11. Temporão JG. A propaganda de medicamentos e o mito da saúde. Rio de Janeiro: Graal; 1986.

12. Palmlund I. The marketing of estrogens for menopausal and postmenopausal women. Psychosom Obstet Gynaecol. 1997; 18: 158-64.

13. Dukes MN. The menopause and the pharmaceutical industry. Psychosom Obstet Gynaecol. 1997; 18: 18-8.

14. Menegon VM. Menopausa: imaginário social e conversa do cotidiano [dissertação mestrado]. São Paulo: Pontifícia Universidade Católica de São Paulo; 1998
15. Ciornai S. Da contracultura à menopausa. São Paulo: Oficina de Letras; 1999.

16. Lemos R. Quarenta: a idade da loba. São Paulo: Globo; 1994.

17. Savoia MG. Estudo exploratório sobre a repercussão psicológica da menopausa em grupo de mulheres de um hospital público [dissertação mestrado]. Campinas: Pontifícia Universidade Católica; 1985.

18. Grant W. Climatério: tempo de mudança [tese de doutorado]. São Paulo: Instituto de Psicologia da Universidade de São Paulo; 1990.

19. Spink PMJ, Frezza R. Práticas discursivas e produção de sentidos: a perspectiva da Psicologia Social. In: Spink MJP, organizadora. Práticas discursivas e produção de sentidos no cotidiano. São Paulo: Cortez; 1997. p.17-39.

20. OMS (Organización Mundial de la Salud). Investigaciones sobre la menopausia en los años noventa. Ginebra; 1996. (Série de Informes Técnicos, 866).

21. Joly M. Introdução à análise da imagem. Lisboa: Edições $70 ; 2001$.

22. Certeau M. A invenção do cotidiano: artes de fazer. São Paulo: Vozes; 1996.

23. Pedro AO, Pinto-Neto AM, Costa-Paiva LHS, Osis MJD, Hardy EE. Síndrome do climatério: inquérito populacional domiciliar em Campinas, São Paulo. Rev Saúde Pública. 2003; 735-42.

24. Sand G. Está quente aqui ou sou eu? São Paulo: Summus; 1995.

25. Mautner AV. Vergonha [Ponto de vista]. Psicologia USP. 2003; 14: 225-9.

26. Héretier F. O pensamento da diferença. Lisboa: Instituto Piaget; 1998.

27. Oliveira MC. Menopausa, reposição hormonal e a construção social da idade madura. In: Néri AL, Debert GG, organizadores. Velhice e sociedade. Campinas: Papirus; 1999. p. 69-86.

Recebido em 2 de dezembro de 2006

Versão final apresentada 28 outubro de 2007

Aprovado em 29 dezembro de 2008 